\title{
AS OUVIDORIAS DOS HOSPITAIS UNIVERSITÁRIOS FEDERAIS SOB A GESTÃO DA EMPRESA BRASILEIRA DE SERVIÇOS HOSPITALARES
}

\author{
Leila Leal Leite ${ }^{1}$
}

\begin{abstract}
Resumo
A Ouvidoria é um instrumento de participação social na gestão democrática por proporcionar ao cidadão oportunidade de ser participante dos processos de gestão. Sobre esse tema desenvolveu-se este estudo, que apresenta o seguinte questionamento: Como as Ouvidorias dos HUFs sob a gestão da EBSERH estão instituídas e desenvolvem os processos de trabaIho e suas inter-relações? Propôs-se como objetivo geral descrever as Ouvidorias dos Hospitais Universitários Federais (HUFs) sob a gestão da Empresa Brasileira de Serviços Hospitalares (EBSERH) e as suas inter-relações. Como objetivos específicos, buscou-se caracterizar as Ouvidorias instituídas nos HUFs no que diz respeito a sua implantação, estrutura física e recursos humanos e descrever os processos de trabalho e a inter-relação das Ouvidorias dos HUFs sob a gestão da EBSERH. Essa pesquisa é de natureza aplicada, com abordagem quanti-qualitativa, descritiva e documental. Os resultados mostraram que as Ouvidorias dos HUFs se assemelham à maioria das Ouvidorias brasileiras, um modelo de Ouvidoria Pública interna. Verificou-se, também, o funcionamento de uma rede de Ouvidorias que favorece a sociedade com um serviço de qualidade.
\end{abstract}

Palavras-chave: Participação e controle social. Ouvidoria. Hospitais Universitários Federais.

DOI:10.37814/2594-5068.2020v3.p147-162

1 Ouvidora do Hospital Universitário da Universidade Federal do Piauí (HU-UFPI). Graduada em Administração Pública e Mestre em Gestão Pública pela Universidade Federal do Piauí (UFPI). (leilaleal@ufpi.edu.br) (ouvidoria. hupi@ebserh.gov.br) 


\section{Abstract}

The Ombudsman's Office is an instrument of social participation in democratic management by providing the citizen with the opportunity to be a participant in the management processes. On this theme was developed this study, which presents the following question: How the HUF Ombudsmen under the management of EBSERH are instituted and develop the work processes and their interrelations? It was proposed as a general objective to describe the Ombudsmen of the Federal University Hospitals (HUFs) under the management of the Brazilian Company of Hospital Services (EBSERH) and their interrelationships. As specific objectives, we sought to characterize the Ombudsman's offices established in HUFs with respect to their implementation, physical structure and human resources and to describe the work processes and the interrelationship of HUF Ombudsmen under the management of EBSERH. This research is applied in nature, with a quantitative-qualitative, descriptive and documentary approach. The results showed that the HUF Ombudsmen are similar to most Brazilian Ombudsmen, a model of internal public Ombudsman. It was also verified the functioning of a network of Ombudsman Offices that favors the society with a quality service.

Keywords: Participation and social control. Ombudsman. Federal University Hospitals. 


\section{INTRODUÇÃO}

A nova conduta de sociabilidade política surgida no Brasil a partir da década de 1980 se deveu a uma conquista de todos os setores sociais que lutaram duramente contra o regime militar instaurado pelo golpe de 1964. Com o estabelecimento dessa nova sociedade, foram criados diversos instrumentos de participação popular que passaram a ser incluídos na ordem jurídica nacional, entre eles, o instituto Ouvidoria Pública, eixo desta pesquisa, que tem como objeto de estudo as Ouvidorias dos Hospitais Universitários Federais (HUFs) sob a gestão da Empresa Brasileira de Serviços Hospitalares (EBSERH).

Essa nova conduta proporciona a propagação da cultura democrática, com implicação na promoção dos direitos individuais e sociais, constitucionalmente garantidos na Constituição Federal de 1988, reconhecida como Carta Magna Democrática Cidadã, marco basilar no aumento da conscientização da sociedade quanto ao exercício de seus direitos perante a gestão pública. Desse modo, o Estado de Direito Democrático passa a ser efetivado à proporção que o cidadão busca usufruir dos seus direitos pela participação popular, com o exercício pleno da democracia e da cidadania (BRASIL,1988).

Segundo OLIVEIRA (2010), atualmente, tem-se um cidadão mais consciente dos seus direitos no tocante ao seu papel como participante social na busca de um espaço aberto para suas conquistas. Nesse sentido, a sociedade exige cada vez mais o cumprimento das políticas de Estado e a prestação de serviços públicos de qualidade. Quanto a isso, destaca-se o sistema brasileiro de saúde pública, bastante discutido e questionado quanto à ineficiência na gestão, em face dos graves problemas que enfrentam os cidadãos que dele dependem.

Nesse contexto, ao longo de décadas, os HUFs enfrentaram diversos problemas relacionados à oferta de serviços de boa qualidade, entre eles, a ineficiência dos gestores, a ausência de metas e de indicadores definidos, a precariedade das condições trabalhistas e, principalmente, a crise financeira que limitou os hospitais em relação aos avanços tecnológicos necessários às novas descobertas terapêuticas.

Diante desse cenário problemático e da crescente reivindicação social por qualidade, o Governo Federal, com vistas à solução, criou a EBSERH para gerenciar os HUFs, com a justificativa de aprimoramento da gestão hospitalar, atendendo às recomendações e determinações do Tribunal de Contas da União (TCU) (BRASIL, 2008).

A EBSERH é uma empresa pública vinculada ao Ministério da Educação e Cultura (MEC), com personalidade jurídica de direito privado, tendo como objetivo gerenciar as instituições de saúde inseridas no Sistema Único de Saúde (SUS) (EBSERH, 2017a). A EBSERH adota a padronização de processos organizacionais para obtenção de uma gestão de qualidade e busca desenvolver estratégias gerenciais que prezam pela efetividade da gestão pública, como a promoção de mudanças na cultura gerencial com vistas ao exercício da cidadania. Com essa expectativa, as Ouvidorias dos HUFs sob a gestão da EBSERH criam uma relação de diálogo com a sociedade, proporcionando a integração do cidadão no monitoramento e na avaliação dos serviços públicos, de modo a garantir o direito de todo cidadão se expressar quanto à satisfação com os serviços das instituições públicas (BRASIL, 2014). 
Mediante a escassez de estudos científicos e de produção técnica que contribuam para o controle administrativo da empresa que gerencia os HUFs e mediante a compreensão de que o instituto Ouvidoria pode contribuir com a gestão pública, o interesse pela realização deste estudo surgiu durante a vivência acadêmica e experiência profissional no cotidiano como Ouvidora do Hospital Universitário da Universidade Federal do Piauí (HU-UFPI). Nesse contexto, emergiu o questionamento que norteou o estudo: Como as Ouvidorias dos HUFs sob a gestão da EBSERH estão instituídas e desenvolvem os processos de trabalho e suas inter-relações?

Com o intuito de responder a essa questão, estabeleceu-se como objetivo geral descrever as Ouvidorias dos Hospitais Universitários Federais (HUFs) sob a gestão da Empresa Brasileira de Serviços Hospitalares (EBSERH) e as suas inter-relações. Como desdobramentos do objetivo geral, estabeleceram-se os objetivos específicos: caracterizar as Ouvidorias instituídas nos HUFs no que diz respeito a sua implantação, estrutura física e recursos humanos e descrever os processos de trabalho e a inter-relação das Ouvidorias dos HUFs sob a gestão da EBSERH.

O caminho metodológico para a obtenção dos resultados envolveu o estudo de natureza aplicada com abordagem investigativa que integra a combinação quanti-qualitativa, por favorecer uma melhor compreensão acerca do objeto estudado. Do ponto de vista dos objetivos, foi realizada pesquisa descritiva, além de ter sido utilizada a pesquisa documental com o intuito de coletar dados complementares por meio de análise do regimento interno e regulamento pessoal da EBSERH, dos contratos de gestão das Universidades Federais com a empresa, dos regulamentos, relatórios de gestão e planos de trabalho anual das Ouvidorias dos HUFs e das atas de reuniões que validam as atividades da Rede Nacional de Ouvidoria dos Hospitais Universitários Federais (RNOHUF).

Os participantes da pesquisa foram 28 (vinte e oito) Ouvidores dos HUFs, correspondendo a $74 \%$ do universo, sendo contemplados os princípios éticos que norteiam a pesquisa científica. Em relação aos procedimentos técnicos, no mês de março de 2017 , fez-se a aplicação de questionário com questões abertas e fechadas, com tratamento e análise dos dados fundamentados nas postulações teóricas, que proporcionaram resultados válidos que dão relevância à pesquisa. Com esse estudo, espera-se poder contribuir com informações para novas pesquisas acerca da importância das Ouvidorias tanto para gestores quanto para a sociedade.

\section{AS OUVIDORIAS DOS HOSPITAIS UNIVERSITÁRIOS FEDERAIS (HUFS)}

Os HUFs agregam duas importantes políticas sociais: a educação e a saúde. Dessa forma, neles se desenvolvem atividades com fins de ensino, pesquisa e extensão, com treinamento em serviço, inovação tecnológica e geração de novos conhecimentos. Para alcançarem suas finalidades, desempenham atividades de assistência à vida humana, pois têm a prerrogativa de manter ensino e assistência de forma articulada e indissociável.

Atualmente, existem 35 (trinta e cinco) Universidades Federais, nas quais se encontram 50 (cinquenta) instituições de saúde, com as seguintes denominações: hospital universitário, hospital-escola, hospital de ensino, de doença tropical, de clínicas e hospital-maternidade. Todos têm atribuições precípuas de ensino, pesquisa e extensão, oferecendo serviços de atenção à saúde de 
média e alta complexidade, sendo $100 \%$ contratualizados com o SUS.

A gestão dessas instituições de saúde está subordinada às Universidades Federais vinculadas ao MEC na qualidade de órgãos encarregados de promover a educação, ou seja, a formação de recursos humanos, cabendo ao Ministério da Saúde (MS) a responsabilidade de garantir a assistência e a promoção da saúde. Vale ressaltar que, até 1960, os HUFs eram custeados somente pelo MEC e não havia pagamento pela prestação de serviços assistenciais (BARROS, 2014).

Nos anos de 1980, o País vivenciou uma crise econômica que resultou na ampliação do déficit financeiro dos HUFs. Desse modo, os valores repassados pelo MEC já não eram suficientes (BARROS, 2014). Assim, os HUFs foram marcados por um longo período de dificuldades financeiras provenientes da escassez de investimento por parte do Governo Federal, afetando a assistência e, consequentemente, a formação dos discentes.

A partir de 1990, os HUFs passaram a ser vinculados a 2 (dois) ministérios, sendo os custeios compartilhados entre o MEC e o MS. Mesmo com essa organização, vivenciaram problemas políticos-organizacionais, assistenciais, de formação profissional e de cunho financeiro, com déficit de recursos. Para BARROS (2014, p. 33), "[...] tal duplicidade é problemática porque não há uma clareza quanto à responsabilização desses entes em relação aos hospitais, ficando a organização, por vezes, sem saber a quem recorrer para solucionar seus problemas".

Diante desse contexto, até 2008, com a realização do $1^{\circ}$ Fórum sobre os Institutos Federais de Ensino Superior (IFES), promovido pelo TCU, a Associação Nacional dos Dirigentes das Instituições Federais de Ensino Superior (Andifes) instituiu uma Comissão Interinstitucional que objetivou discutir o modelo de financiamento dos HUFs (BRASIL, 2008). Essa Comissão identificou, nos HUFs, várias falhas, tais como a falta de planejamento dos governos, instalações físicas deficitárias, insuficiência de recursos humanos devido ao elevado número de aposentadorias, falta de política de reposição do quadro de profissionais, desfalcado pela falta de concursos, desigualdades salariais forçando a busca de outros vínculos e terceirização de mão de obra, proibida na época pelo TCU. Diante dessa situação, alguns hospitais fecharam serviços, desativaram leitos e reduziram a capacidade de oferta de serviços assistenciais à comunidade (BRASIL, 2008).

Diante dessa situação, o Governo Federal criou, por meio do Decreto n 7.082/2010, o Programa Nacional de Reestruturação dos Hospitais Universitários Federais (Rehuf), para a realização da reforma universitária e reestruturação dos HUFs, dotando-os de condições materiais e institucionais para desempenharem plenamente suas funções na dimensão de ensino, pesquisa, extensão e assistência à saúde. Esse Programa determinou ainda o papel e as funções concernentes ao MEC, ao MS e ao Ministério do Planejamento, Desenvolvimento e Gestão (MPOG), apresentando as seguintes diretrizes do Rehuf: melhorias no processo de gestão, adequação da estrutura física, recuperação do parque tecnológico, reestruturação de recursos humanos, aprimoramento e avaliação permanente dos serviços e incorporação de novas tecnologias no tocante ao ensino, pesquisa e assistência à saúde (BRASIL, 2010).

Para atender aos objetivos do programa Rehuf, de modo a suprir as deficiências e mudar a realidade vivenciada nos HUFs, o Governo Federal sancionou a Lei $n^{\circ}$ 12.550/2011 e autorizou o Poder Executivo a criar a empresa pública vinculada ao MEC, nominada EBSERH, a qual tem caráter jurídico de direito privado, regime de trabalho celetista, patrimônio próprio, prazo de duração in- 
determinado. Essa empresa está sediada em Brasília, com competência de administrar as unidades hospitalares no âmbito do SUS, prestando serviços de assistência ambulatorial, médico-hospitalar e de embasamento diagnóstico e terapêutico à população (BRASIL, 2011).

Nesse contexto, em concordância com a EBSERH, os HUFs atuam na assistência à saúde, no campo do ensino, na formação dos profissionais de saúde e áreas afins, na inovação tecnológica e no desenvolvimento de novas abordagens nas áreas acadêmicas. Esses hospitais ofertam serviços de atenção à saúde gratuitamente por meio do acesso regulado e integrado à rede de urgência e emergência no âmbito do SUS.

A adesão voluntária à EBSERH deve ser manifestada pelo interesse do reitor da IFES em celebrar a parceria de gestão. Após esse momento, o hospital passa a vivenciar um processo de análise e diagnóstico, o qual subsidia a elaboração do contrato que estabelece obrigações, metas de desempenho, indicadores, prazos de execução, sistemática de acompanhamento e avaliação, consoante o $\S 4^{\circ}$ do artigo $2^{\circ}$ do Regimento Interno: "A execução das atividades da EBSERH, por intermédio de suas filiais e unidades descentralizadas, dar-se-á por meio da celebração de contrato específico para esse fim [...]" (EBSERH, 2016a).

Após a identificação das necessidades da instituição contratante e a realização do contrato com a EBSERH, é elaborado, com vigência anual, o Plano de Reestruturação, estabelecendo as metas em curto prazo para adaptação dos processos internos e da estrutura organizacional. Durante esse período, é implantado o Plano Diretor Estratégico (PDE), com duração de 2 (dois) anos, o qual pactua as metas de médio e longo prazo conforme o processo de diagnóstico situacional, com a detecção de necessidades materiais e de dimensionamento de pessoal. A empresa realiza o monitoramento e a avaliação da execução dos planos nos HUFs e articula com o MPOG a autorização das solicitações dos cargos e suas respectivas quantidades, a serem investidos por meio de concurso público (EBSERH, 2016a).

Atualmente, a referida empresa é responsável pela gestão de 40 (quarenta) HUFs que realizaram parceria de gestão por interesse do reitor da IFES. Esses hospitais estão geograficamente localizados em todas as regiões do País, sendo que 4 (quatro) estão na região Norte, 17 (dezessete) no Nordeste, 5 (cinco) no Centro-Oeste, 8 (oito) no Sudeste e 6 (seis) na região Sul. Apenas 10 (dez) HUFs ainda não realizaram a adesão à EBSERH.

Os HUFs são gerenciados por um colegiado executivo, conhecido como equipe de governança, a qual, conforme o artigo 60 do Regimento Interno da EBSERH, deve ser composta por: "a) Superintendente do hospital; b) um Gerente de Atenção à Saúde; c) um Gerente Administrativo; e d) um Gerente de Ensino e Pesquisa, quando se tratar de hospitais universitários ou de ensino" (EBSERH, 2016a).

A estrutura de governança dos HUFs conta com segmento de apoio à gestão, formado por Secretaria, Assessoria Jurídica, Assessoria de Planejamento, Ouvidoria, Comissões Assessoras, Setor de Gestão e Informática. Conta também com o segmento de controle e fiscalização formado por Auditoria e Conselho Consultivo.

A EBSERH prevê a implantação de Ouvidorias a partir da sua estrutura organizacional. $\mathrm{Na}$ empresa sede, é institucionalizada a Ouvidoria-Geral, e nos HUFs, a Ouvidoria hospitalar, ambas inseridas no segmento de apoio à gestão e representadas legalmente por um Ouvidor titular que 
“[...] são aqueles relacionados às atividades e responsabilidades pela gestão técnico-administrativa e de assessoramento [...]" (EBSERH, 2016b, p. 3).

A Ouvidoria-Geral da EBSERH, vinculada ao presidente, é instância de controle e participação social. Na descrição das atribuições dos cargos, o Ouvidor-Geral tem a atribuição de coordenar os serviços de atendimento aos cidadãos, direta ou indiretamente, relacionados à EBSERH, encaminhando as reclamações, elogios, sugestões ou denúncias, visando ao aperfeiçoamento e à contínua melhoria dos processos administrativos (EBSERH, 2013).

O Regulamento da Ouvidoria-Geral da EBSERH prevê autonomia plena, independência no exercício das atribuições do Ouvidor e a garantia da sua participação nas reuniões da Diretoria Executiva, como ouvinte, a fim de esclarecer as questões suscitadas e de propor melhorias das rotinas administrativas e institucionais, com o dever de resguardar o sigilo das fontes de informações (EBSERH, 2012a).

Por seu turno, as Ouvidorias das unidades hospitalares apresentam-se como órgãos descentralizados de relevância na comunicação com dirigentes, docentes, discentes, pesquisadores, prestadores de serviços, fornecedores, servidores, empregados e cidadãos em geral, instâncias que contribuem para o aperfeiçoamento do modelo de gestão, das ações institucionais e para melhoria dos processos internos (EBSERH, 2012a).

As Ouvidorias dos HUFs integrantes da RNOHUF conta com 40 (quarenta) Ouvidorias hospitalares, com a participação de 38 (trinta e oito) Ouvidores. Vale ainda ressaltar que, devido à constituição de 2 (dois) Complexos Hospitalares, existem 2 (dois) Ouvidores que representam 2 (duas) Ouvidorias hospitalares, cada. A inserção de uma nova Ouvidoria na rede se faz com a participação do Ouvidor hospitalar na oficina de alinhamento de ações durante o evento anual intitulado Encontro Nacional de Ouvidores dos Hospitais Universitários Federais promovido pela Ouvidoria-Geral.

Conclui-se, portanto, que as organizações públicas de saúde têm buscado cada vez mais otimizar os serviços ofertados, prezando pela qualidade no atendimento, a fim de atender às expectativas de seus clientes, focando no processo de melhoria contínua. Nessa relação, surge e se consolida um espaço democrático de garantia dos direitos dos cidadãos.

\section{CARACTERIZAÇÃO DAS OUVIDORIAS INSTITUÍDAS NOS HUFS}

O estudo possibilitou a descrição e análise das Ouvidorias dos HUFs sob a gestão da EBSERH. Os dados provenientes da pesquisa documental e da aplicação do questionário foram agrupados, submetidos a análises estatísticas e apresentados em tabelas, gráficos e quadros.

O gráfico 1 apresenta os motivos pelos quais as Ouvidorias foram implantadas no HUFs. Nesse sentido, $78,6 \%$ dos Ouvidores responderam que a decisão de implantar 22 (vinte e duas) Ouvidorias foi por deliberação da gestão, sendo que, destas, 8 (oito) Ouvidorias foram criadas após a realização contratual dos hospitais com a EBSERH; $14,3 \%$ informaram que a implantação se deu por iniciativa de políticas de saúde do SUS; e 7,1\% alegaram outros motivos, como obediência aos instrumentos normativos devido à exigência da contratualização da instituição com o SUS e a iniciativa em conjunto da gestão da instituição e do conselho local de saúde. 


\section{GRÁFICO 1 - Motivos da Implantação das Ouvidorias dos HUFs}

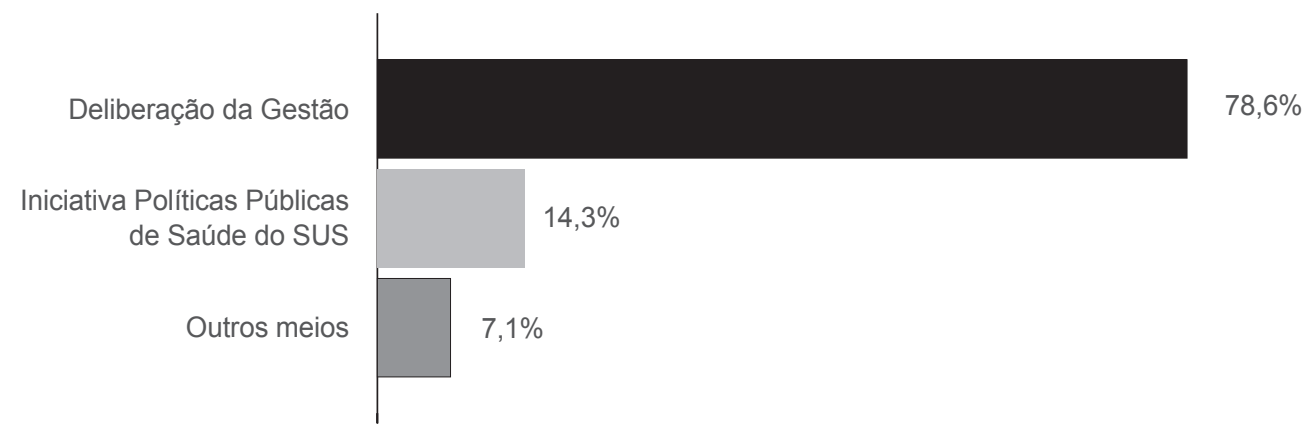

Fonte: Pesquisa direta, 2017

O gráfico 2 demonstra que $71,4 \%$ dos HUFs implantaram Ouvidorias antes da realização dos seus contratos com a EBSERH, correspondendo a 20 (vinte) instituições hospitalares. Para atender às diretrizes da referida empresa - $28,6 \%$-, instituíram novas Ouvidorias, ou seja, foram implantadas 8 (oito) Ouvidorias hospitalares após o início da gestão da EBSERH.

\section{GRÁFICO 2 - Implantação das Ouvidorias por Contratações com a EBSERH}

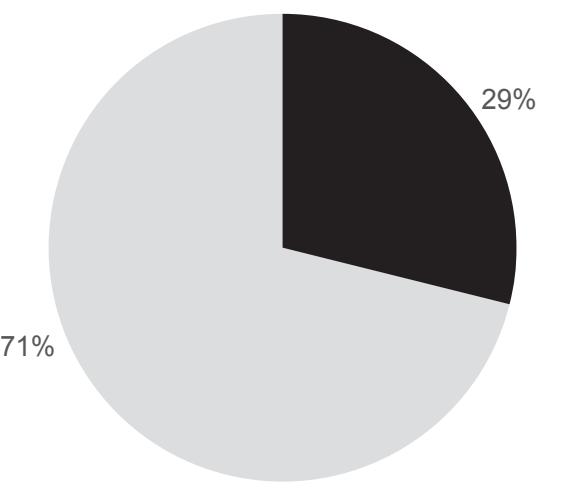

Das Ouvidorias implantadas antes do contrato das instituições com a EBSERH, $60,0 \%$ faziam parte do organograma, com $40,0 \%$ fora da estrutura organizacional. Em relação à subordinação hierárquica dessas Ouvidorias, uma era vinculada ao chefe de gabinete, e outra, ao Serviço Social, 
enquanto as demais Ouvidorias eram vinculadas ao diretor-geral, gestor máximo da instituição, que representa atualmente a figura do superintendente, segundo a nova nomenclatura no desenho organizacional.

Em relação à estrutura física, os dados mostram que 46,4\% das Ouvidorias dos HUFs dispõem apenas de uma sala para o desempenho das atividades laborais, ao passo que $14,3 \%$ funcionam em três salas, sendo que uma Ouvidoria não possui sala exclusiva para a realização de suas atividades, compartilhando a ambiência com outros setores, mas a instituição informa que estão sendo realizados arranjos estruturais graças à reforma predial, conforme a tabela 1.

\section{TABELA 1 - Aspectos da Estrutura Física das Ouvidorias dos HUFs}

\begin{tabular}{|l|l|l|}
\hline Variáveis & $N^{\circ}$ & $\%$ \\
\hline Quantitativo de salas para o serviço de Ouvidoria & \multicolumn{2}{l|}{} \\
\hline Uma sala & 13 & $46,4 \%$ \\
\hline Duas salas & 10 & $35,7 \%$ \\
\hline Três salas & 04 & $14,3 \%$ \\
\hline Sala compartilhada com outro serviço & 01 & $3,6 \%$ \\
\hline Total & 28 & $100,0 \%$ \\
\hline Sala para atendimento individual & \multicolumn{2}{|l|}{} \\
\hline Sim & 13 & $46,4 \%$ \\
\hline Não & 15 & $53,6 \%$ \\
\hline Total & 28 & $100,0 \%$ \\
\hline A localização da sala da Ouvidoria é de fácil acesso \\
\hline Sim & 26 & $92,9 \%$ \\
\hline Não & 02 & $7,1 \%$ \\
\hline Total & 28 & $100,0 \%$ \\
\hline Existem sinalizações indicando a localização da Ouvidoria \\
\hline Sim & 18 & $64,3 \%$ \\
\hline Não & 10 & $35,7 \%$ \\
\hline Total & 28 & $100,0 \%$ \\
\hline
\end{tabular}

Fonte: Pesquisa direta, 2017

Conforme demonstra a tabela $1,53,6 \%$ das Ouvidorias dos HUFs não possuem sala para atendimento individual, enquanto $46,4 \%$ são contempladas com esse espaço físico. Dessas, 4 (quatro) Ouvidores declararam que suas Ouvidorias dispõem de duas salas, sendo uma destinada a atendimento individual, mas há necessidade de reformas prediais para a ampliação das salas e a proteção acústica da sala de atendimento individual.

Para o bom desempenho, é necessário um espaço físico que permita à equipe de Ouvidoria desenvolver suas atividades à luz das premissas essenciais desse serviço - confidencialidade, 
imparcialidade e independência. Nesse aspecto, segundo a percepção dos Ouvidores, 39,3\% das Ouvidorias dos HUFs possuem estrutura física adequada, mesmo que 2 (duas) não sejam contempladas com salas para atendimento privativo, enquanto $60,7 \%$ das Ouvidorias não possuem estrutura física adequada, conforme demonstrado no gráfico 3.

\section{GRÁFICO 3 - Estrutura Física das Ouvidorias}

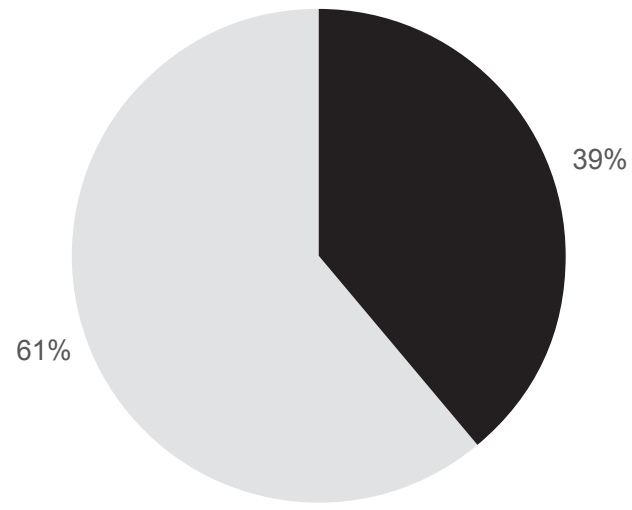

No que diz respeito aos recursos humanos, a tabela 2 mostra que 42,9\% das Ouvidorias dos HUFs compõem suas equipes com 2 (dois) ou 3 (três) trabalhadores, havendo 2 (duas) Ouvidorias $(7,1 \%)$ compostas apenas pelo próprio Ouvidor. Em função do volume de atividades a serem desempenhadas, isso demonstra um quadro de pessoal insuficiente. Esse mesmo quantitativo $(7,1 \%)$ possui equipes com 4 (quatro) ou mais trabalhadores, um número considerado suficiente para o desempenho das atividades da Ouvidoria.

\section{TABELA 2 - Quantitativo de Trabalhadores Lotados em Cada Ouvidoria}

\begin{tabular}{|l|l|l|}
\hline Quantitativo de trabalhadores / Ouvidoria & $\mathrm{N}^{\circ}$ & $\%$ \\
\hline 1 trabalhador* & 02 & $7,1 \%$ \\
\hline 2 trabalhadores & 12 & $42,9 \%$ \\
\hline 3 trabalhadores & 12 & $42,9 \%$ \\
\hline$\geq 4$ trabalhadores & 02 & $7,1 \%$ \\
\hline Total & 28 & $100,0 \%$ \\
\hline
\end{tabular}

Fonte: Pesquisa direta, 2017 
Nota: *1 trabalhador corresponde ao próprio Ouvidor.

As Ouvidorias dos HUFs contam com 73 (setenta e três) trabalhadores, consoante o gráfico 4, dos quais, 38,4\% ocupam o cargo de Ouvidor, 42,5\% desempenham funções de assistente administrativo, 11\%, de secretariado, e 8,2\%, de recepcionistas. Apenas 2 (duas) Ouvidorias contam com bolsistas, um desempenhando a função de secretário, e o outro, a de recepcionista.

\section{GRÁFICO 4 - Quantitativo de Trabalhadores por Cargo}

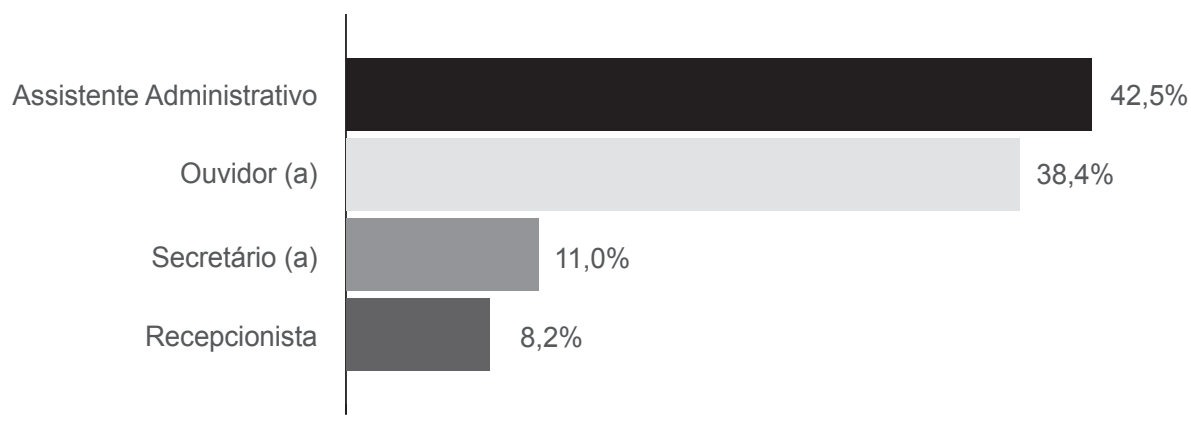

Fonte: Pesquisa direta, 2017

Os resultados mostram que 5 (cinco) Ouvidorias têm no seu quadro de trabalhadores funcionários com Regime Jurídico Único (RJU) que estão desempenhando função diferente do cargo efetivado na instituição, havendo, no exercício da função de assistente administrativo: 1 (uma) enfermeira, 4 (quatro) técnicos de enfermagem, 1 (um) auxiliar operacional de serviços diversos e 1 (um) porteiro. Há também 1 (um) auxiliar de enfermagem na função de recepcionista.

Os Ouvidores declararam que as Ouvidorias deveriam ser constituídas por equipe mínima de três pessoas: um Ouvidor, um assistente administrativo e um secretário, sendo que o quantitativo ideal para compor a equipe de Ouvidoria seria de quatro trabalhadores, ou seja, a equipe mínima com acréscimo de um assistente administrativo para as atividades do SIC, ou cinco trabalhadores, com a inclusão de um Ouvidor adjunto.

\section{PROCESSOS DE TRABALHO E A INTER-RELAÇÃO DAS OUVIDORIAS DOS HUFS}

As declarações dos entrevistados mostram, no quadro 1, as ações sugeridas pela Ouvidoria-Geral da EBSERH e desempenhadas pelas Ouvidorias dos HUFs. Entre essas atividades, a maioria das Ouvidorias passou a realizar Pesquisa de Satisfação do Usuário (PSU), adotou instrumento normativo e teve uma participação assídua nos eventos, capacitações e treinamentos. 


\section{QUADRO 1 - Ações Desempenhadas pelas Ouvidorias dos HUFs Sugeridas pela Ouvidoria-Geral da EBSERH}

\begin{tabular}{|c|c|c|}
\hline TEMA & CATEGORIA & CONTEXTO \\
\hline \multirow{7}{*}{ 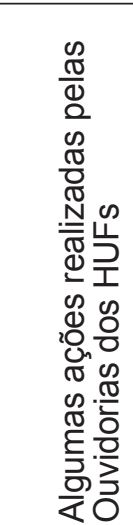 } & $\begin{array}{l}\text { Realização de Pesquisa } \\
\text { de Satisfação do Usuário }\end{array}$ & $\begin{array}{l}\text { Ouv17: Realização da Pesquisa de Satisfação em dois ciclos } \\
\text { [...] }\end{array}$ \\
\hline & \multirow{3}{*}{$\begin{array}{l}\text { Adesão de instrumento } \\
\text { normativo }\end{array}$} & Ouv12: [...] formulação do regulamento da Ouvidoria [...] \\
\hline & & Ouv14: Construção da normatização [...] \\
\hline & & $\begin{array}{l}\text { Ouv22: Regulamento padrão para toda a rede, normas e } \\
\text { rotinas }[\ldots]\end{array}$ \\
\hline & \multirow{3}{*}{$\begin{array}{l}\text { Participação nos even- } \\
\text { tos, capacitações e } \\
\text { treinamentos }\end{array}$} & Ouv2: [...] participação nos eventos de Ouvidoria. \\
\hline & & Ouv23: [...] orientações técnicas [...] \\
\hline & & $\begin{array}{l}\text { Ouv26: a EBSERH propõe que o Ouvidor se qualifique através } \\
\text { de videoconferência, cursos e encontros. }\end{array}$ \\
\hline
\end{tabular}

Fonte: Pesquisa direta, 2017

Quanto à realização da PSU, ANDRADE (2017, p. 190) afirma que "[...] outra forma importante de participação do usuário na gestão é através da Pesquisa de Satisfação realizada pelas Ouvidorias dos HUs". Essa estratégia de avaliação é uma atividade realizada em dois ciclos por ano e executada simultaneamente por todas as Ouvidorias dos HUFs, como declarado pelo Ouv17: "Realização da pesquisa de satisfação em dois ciclos [...]".

Quanto à adesão voluntária ao instrumento normativo, a formulação do Regulamento Interno da Ouvidoria, proposto como modelo padrão, foi realizada por $28,6 \%$ das Ouvidorias, como mencionado pelos Ouv12: "[...] formulação do regulamento da Ouvidoria [...]" e Ouv22: "Regulamento padrão para toda a rede, normas e rotinas [...]". Vale enfatizar que essa ação normativa foi adotada pelas Ouvidorias que não possuíam o devido instrumento.

Os Ouvidores $(17,9 \%)$ reconhecem que a participação em eventos, capacitações e treinamentos com temáticas relacionadas à Ouvidoria são outras ações sugeridas, como afirma o Ouv26: "[...] a EBSERH propõe que o Ouvidor se qualifique através de videoconferência, cursos e encontros". Por sua vez, $14,3 \%$ realizam a produção de relatórios com a periodicidade anual, sendo que esse mesmo quantitativo elaborou ou atualizou a carta de serviços ao cidadão.

Conforme análise documental do Regulamento da Ouvidoria-Geral da EBSERH (2012a), essa entidade coordena a RNOHUF com o intuito de que as ações das Ouvidorias dos HUFs estejam alinhadas mediante padronização dos processos e unificação dos sistemas de dados, de modo que sejam integrantes dessa rede, como previsto no Regimento Interno (EBSERH, 2016a). É, assim, esperável que os Ouvidores busquem manter uma aproximação entre eles, o que favorece a efetivação da inter-relação das Ouvidorias dos HUFs. 
O quadro 2 demonstra as experiências que os Ouvidores adquiriram na rede.

\section{QUADRO 2 - Experiências Adquiridas na RNOHUF}

\begin{tabular}{|c|c|c|}
\hline TEMA & CATEGORIA & CONTEXTO \\
\hline \multirow{6}{*}{ 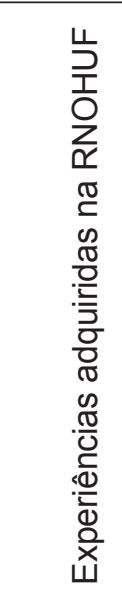 } & \multirow{2}{*}{$\begin{array}{l}\text { Troca de } \\
\text { experiências }\end{array}$} & $\begin{array}{l}\text { Ouv23: Quando se trabalha em rede, todas as experiências posi- } \\
\text { tivas observadas podem ser adaptadas à nossa realidade. Isso é } \\
\text { muito positivo. }\end{array}$ \\
\hline & & $\begin{array}{l}\text { Ouv27: As trocas de experiências por videoconferência têm sido } \\
\text { muito positivas na implementação de ações, no sentido de aprimorar } \\
\text { o trabalho que vem sendo realizado. }\end{array}$ \\
\hline & \multirow{2}{*}{$\begin{array}{l}\text { Melhoria da pesqui- } \\
\text { sa de Satisfação do } \\
\text { Usuário }\end{array}$} & $\begin{array}{l}\text { Ouv7: [...] melhoria no processo de aplicação da Pesquisa de Satis- } \\
\text { fação do Usuário. }\end{array}$ \\
\hline & & $\begin{array}{l}\text { Ouv17: [...] apresentação de novos relatórios da Pesquisa de Satis- } \\
\text { fação do Usuário [...] }\end{array}$ \\
\hline & \multirow{2}{*}{$\begin{array}{l}\text { Atualização do ins- } \\
\text { trumento normativo }\end{array}$} & $\begin{array}{l}\text { Ouv2: a experiência na rede proporcionou a atualização do regula- } \\
\text { mento e dos fluxos de trabalho [...] }\end{array}$ \\
\hline & & $\begin{array}{l}\text { Ouv13: [...] algumas ações desenvolvidas a partir da rede foram } \\
\text { reajustes no regulamento interno [...] }\end{array}$ \\
\hline
\end{tabular}

Fonte: Pesquisa direta, 2017

No quadro 2, observam-se várias percepções positivas apresentadas por 82,1\% dos Ouvidores. Desses, 64,3\% declararam o que a participação na rede proporciona, como o Ouv23: "Quando se trabalha em rede, todas as experiências positivas observadas podem ser adaptadas à nossa realidade. Isso é muito positivo", e o Ouv27: "As trocas de experiências por videoconferência têm sido muito positivas na implementação de ações, no sentido de aprimorar o trabalho que vem sendo realizado".

No desenvolvimento de um trabalho em rede de Ouvidoria, deve existir uma integração sistêmica que possibilite o seu efetivo funcionamento, mas, para isso, não se faz necessária nenhuma subordinação hierárquica, mas, sim, uma rede colaborativa que atue de forma contínua, presencial ou virtual, a fim de que a troca de conhecimentos possibilite uma evolução do coletivo, na medida em que ela gera inovações que poderão ser aplicadas no âmbito do trabalho de forma geral (BRASIL, 2012). Essas trocas de informações entre os Ouvidores poderão estar relacionadas com "[...] conceitos, fluxos, procedimentos internos, normativos, experiências e relações internas e externas que proporcionam um crescimento mútuo das Ouvidorias numa teia de relações onde todas ganham" (BRASIL, 2012, p. 8).

O fortalecimento da rede se faz com maior articulação entre os Ouvidores, o que resulta em pactuações deliberadas coletivamente, proporcionando o alinhamento das ações entre as Ouvidorias, como afirmam $17,9 \%$ dos Ouvidores. Esse alinhamento é essencial para o fortalecimento das Ouvidorias, permitindo que possam ofertar um serviço de qualidade mediante ações comuns a 
todas as que participam da rede. Dessa forma, o cidadão receberá um atendimento de qualidade, uniforme e padronizado das Ouvidorias dos HUFs.

Para o aprimoramento da qualidade do atendimento, a PSU tem a missão de avaliar o grau de satisfação dos usuários sob a gestão da EBSERH, conforme descrito no plano de trabalho (EBSERH, 2017b). Com o trabalho da rede, algumas Ouvidorias, que anteriormente realizavam essa atividade em outro formato e com uso de diferentes instrumentos para a sua aplicação, aperfeiçoaram, conforme declarado por $17,9 \%$ dos Ouvidores e representado pelo Ouv7: "[...] melhoria no

processo de aplicação da Pesquisa de Satisfação do Usuário" e pelo Ouv17: "[...] apresentação de novos relatórios da Pesquisa de Satisfação do Usuário [...]".

Com a definição de melhores práticas para a atuação das Ouvidorias, se faz necessário atualizar as normas que respaldam suas atribuições e competências. É notório observar que as Ouvidorias com regulamentos internos aprovados e fluxo de trabalho estabelecido antes da criação da rede atualizaram seus instrumentos normativos após a participação de 14,3\% dos Ouvidores na rede, o que resultou em novos entendimentos sobre as normativas que regem as ações das suas Ouvidorias. Conforme demonstrado pelos Ouv2, "A experiência na rede proporcionou a atualização do regulamento e dos fluxos de trabalho [...]", e Ouv13: "[...] algumas ações desenvolvidas a partir da rede foram: reajustes no regulamento interno [...]".

Mesmo que existam especificidades de cada instituição, as características gerais são semeIhantes, pois as Ouvidorias estão inseridas nas instituições de saúde que agregam o ensino. Essas especificidades não inviabilizam a institucionalização de uma rede que contemple a participação e a integração dos Ouvidores.

\section{CONCLUSÃO}

Uma Ouvidoria Pública considerada atuante e proativa cumpre com a missão de garantir um espaço para a efetiva democracia participativa, ao assegurar o canal de comunicação entre os cidadãos e a Administração Pública para manutenção do atendimento de forma ágil e resolutiva das situações apresentadas. A eficácia da Ouvidoria está relacionada diretamente com a contribuição e colaboração da instituição quanto à receptividade e à resolutividade das demandas, promovendo um clima democrático e participativo.

Os resultados das pesquisas, contudo, indicam um distanciamento entre o propósito ideal das Ouvidorias dos HUFs e suas atuais condições concretas tanto no universo do modelo adotado de Ouvidorias Públicas quanto no universo dos seus processos de trabalho. Ao compreender que essas Ouvidorias participam de uma rede, devendo, portanto, estar alinhadas de modo a ter êxito em suas atuações, é possível identificar algumas divergências quanto a constituição, funcionamento e desenvolvimento de algumas atividades.

É notório que existem diferenças entre as Ouvidorias quanto a estruturação física (número de salas, localização, sinalização, sala com proteção acústica para atendimento privativo e ambiência com recursos de acessibilidade), recursos humanos, instrumentos normativos, organização dos serviços por meio de planos de trabalho, utilização da diversidade de sistemas tecnológicos e emis- 
são de relatórios estatísticos e de gestão.

Os resultados da pesquisa, contudo, indicam que existem diferenças entre as Ouvidorias dos HUFs, mas que a inter-relação entre elas permite que seja formalizada e consolidada a constituição de processo de trabalho em rede, pois essas Ouvidorias possuem o interesse único e exclusivo de servir ao público com qualidade, zelando pelo exercício ético da profissão.

A Ouvidoria-Geral da EBSERH pode contribuir com as Ouvidorias hospitalares, uma vez que sua coordenação possibilita a superação das dificuldades encontradas na implementação das ações das Ouvidorias dos HUFs, tanto nas condições estruturais quanto nas administrativas. Dessa forma, o avanço dessas Ouvidorias na institucionalização, somado às suas competências, reflete-se na virtude de contemplar totalmente a efetividade de sua existência.

\section{REFERÊNCIAS}

ANDRADE, Nelma Gomes Bezerra de. Ouvidoria hospitalar como espaço de participação dos cidadãos na gestão dos serviços públicos. In: PODESTÁ JÚNIOR, Arnaldo; PFAFFENSELLER, Ana Cláudia de Almeida; OLIVEIRA, Alan Santos de (Org.). Ouvidoria no Brasil e seus desafios: olhares de norte a sul, relatos de experiência em Instituições de Ensino Superior e hospitais universitários. Florianópolis: Tribo da Ilha, 2017. p. 185-195.

BARROS, Renata Tenório de. Empresa Brasileira de Serviços Hospitalares: uma análise sobre sua gestão no contexto institucional do Hospital das Clínicas da UFPE. 2014. 157 f. Tese (Mestrado Profissional em Gestão Pública para o Desenvolvimento do Nordeste) - Universidade Federal de Pernambuco, Recife, 2014.

BRASIL. Constituição da República Federativa do Brasil de 1988. Disponível em: <http://www.planalto.gov.br/ccivil_03/Constituicao/Constituicao.htm>. Acesso em: 24 jun. 2019.

Tribunal de Contas da União. Fórum sobre as Instituições Federais de Ensino Superior. O TCU promove a

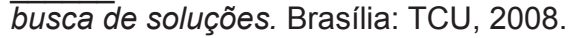

Decreto $n^{\circ} 7.082$ de 27 de janeiro de 2010. Institui o Programa Nacional de Reestruturação dos Hospitais Universitários Federais - REHUF, dispõe sobre o financiamento compartilhado dos hospitais universitários federais entre as áreas da educação e da saúde e disciplina o regime da pactuação global com esses hospitais. Diário Oficial da União, Brasília, DF, 27 janeiro de 2010. Disponível em: <http://www.planalto.gov.br/ccivil_03/_ato2007-2010/2010/ decreto/d7082.htm>. Acesso em: 28 jun. 2019.

Lei $n^{\circ} 12.550$ de 15 de dezembro de 2011. Autoriza o Poder Executivo a criar a empresa pública denominada Empresa Brasileira de Serviços Hospitalares - EBSERH e dá outras providências. Diário Oficial da União Brasília, DF, 16 dez. 2011. Disponível em: <http://www.planalto.gov.br/ccivil_03/_ato2011-2014/2011/lei/l12550.htm>. Acesso em: 05 jun. 2019.

Ministério da Transparência, Fiscalização e Controladoria-Geral da União. Ouvidoria-Geral da União. Orientações para implantação de Unidade de Ouvidoria. 5. ed. Brasília, 2012.

Ministério da Saúde. Secretaria de Gestão Estratégica e Participativa. Departamento de Ouvidoria-Geral do SUS. Manual das Ouvidorias do SUS. Brasília: Ministério da Saúde, 2014.

EBSERH. Empresa Brasileira de Serviços Hospitalares. Resolução da Diretoria Executiva $n^{\circ} 21 / 2012$. Aprova o Regulamento da Ouvidoria-Geral. Brasília, 2012a. Disponível em: <http://www.ebserh.gov.br/documents/15804/0/Regulamento+da+Ouvidoria+-+Resolu\%C3\%A7\%C3\%A3o+21.pdf/6966fd54-737a-4b93-a8a3-f52c323cf935>. Acesso em: 07 jun. 2019.

. Resolução de Diretoria Executiva n 008/2012. Brasília, 2012b. Disponível em: <http://www. ebserh.gov.br/documents/16888/0/10.+Resolu\%C3\%A7\%C3\%A3o+n\%C2\%BA+8\%252c+de+24+de+setembro+de+2012+\%281\%29.pdf/86483b02-914d-4525-aeb2-1188457cfde7>. Acesso em: 07 jun. 2019.

Descrição sumária das atribuições dos cargos da EBSERH/Sede. Brasília, 2013. Disponível em: <http://ebserh.gov.br/documents/15792/106349/Atribuicoes_Descricao_Sumaria_Ebserh_Sede_v2.pdf/813375d3-66f1-482e-863c-771afb427b1c>. Acesso em: 07 jun. $201 \overline{9}$. 
Regimento Interno: Hospitais Universitários Federais. $3^{a}$ revisão. Brasília, 2016a. Disponível em: <http://www.ebserh.gov.br/documents/15796/112576/Regimento+Interno+Aprovado+CA+12052016.pdf/fda5583a-4f34-44ed-b75b-ea96c1332b4b>. Acesso em: 06 jun. 2019.

Plano de cargos em comissão e funções gratificadas. Remuneração presidente e diretores. Honorários conselheiros. Brasília, 2016b. Disponível em: <http://www.ebserh.gov.br/documents/15796/65717/Plano_de CC_e_FG_Presidente_Diretores_Conselheiros_EBSERH_otubro+de+2016.pdf/e3441893-8422-469b-8296-329c3 $\bar{c}$ $45 \overline{3 d} \overline{c a}>$. Ācesso em: 06 jun. $20 \overline{19}$.

Hospitais Universitários: Apresentação. Brasília, 2017a. Disponível em: <http://www.ebserh.gov.br/web/portal-ebserh/apresentacao1>. Acesso em: 05 jun. 2019.

Plano de Trabalho da Pesquisa de Satisfação do Usuário. Brasília, 2017b. Disponível em: <http:// www.ebserh.gov.br/documents/15804/0/1\%C2\%BA+Ciclo-2017.pdf/80ea7ac3-4ec8-434d-9fd7-9f4922ec405e> Acesso em: 06 jun. 2019.

OLIVEIRA, João Elias de. A Ouvidoria como um sistema de fomentação da cidadania. 2010. Disponível em: <www. abonacional.org.br/textos2.asp>. Acesso em: 27 jun. 2019. 